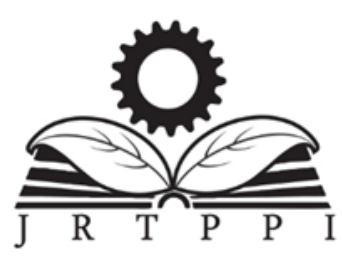

Vol. 11 No. 2 (2020) 11-18

Jurnal Riset

Teknologi Pencegahan Pencemaran Industri

Kementerian

Perindustrian

REPUBLIK INDONESIA

Journal homepage : http://www.jrtppi.id

\title{
Optimization of Production Activated Carbon for Removal of Pharmaceuticals Wastewater Using Taguchi Method and Grey Relational Analysis
}

\section{Tri Hadi Jatmiko ${ }^{1}$}

${ }^{1}$ Balai Penelitian Teknologi Bahan Alam, Lembaga Ilmu Pengetahuan Indonesia

\author{
A R T IC L E I N F O \\ Article history: \\ Received 03 July 2020 \\ Received in revised form 16 October \\ 2020 \\ Accepted 02 November 2020 \\ Available online 19 November 2020 \\ Keywords : \\ Activated carbon \\ Taguchi \\ Grey Relational Analysis
}

\begin{abstract}
A B S T R A C T
The development of the pharmaceutical industry has led to increased environmental pollution by pharmaceutical wastewater. This encourages efforts to develop effective and inexpensive pharmaceutical wastewater management. One effort to handle pharmaceutical wastewater is to use activated carbon. In the manufacture of activated carbon there are several factors that affect the quality and performance of activated carbon produced. This research seeks to determine the optimum factors in making activated carbon and study its application in adsorbing pharmaceutical wastewater contain carbamazepine, sulfamethoxazole, and paroxetine. Multiresponse analysis based on the Taguchi Grey relational analysis method was used to determine the optimum conditions. The most influential factors in the production of activated carbon, respectively, were pyrolysis temperature $\left(800^{\circ} \mathrm{C}\right)$, ratio of precursors and activating agents $(1: 1)$, residence time (150 minutes) and finally the type of activator $(\mathrm{KOH})$.
\end{abstract}

\section{INTRODUCTION}

Population growth and the development of science, especially in the fields of health and pharmaceutical, had encouraged the increasing consumption of drugs so that the production of drugs had also increased rapidly. The growth of the pharmaceutical industry raises problems in the treatment of drug industry waste. Some pharmaceutical industry wastes, although in small amounts, are hazardous for the environment, so some pharmaceutical ingredients have become hazardous waste according to regulations in Europe. Pharmaceutical wastewater contains active compounds as drug residue with toxic substances, volatile organic compound that dangerous for the environment. Pharmaceutical wastewater also high in chemical oxygen demand and biological oxygen demand (Gadipelly et al., 2014; Guo, Qi, \& Liu, 2017; Jaria, Silva, et al., 2019; Li \&
Li, 2015; Pal, 2018; Pereira, Calisto, \& Santos, 2019; Rana et al., 2017)

Various efforts have made to prevent pharmaceutical pollution in the environment. Adsorption is one of the most promising techniques for processing pharmaceutical wastewater. One of the promising efforts to process pharmaceutical wastewater is adsorption with activated carbon (Jaria, Calisto, et al., 2019; Jaria, Silva, et al., 2019; Pereira et al., 2019; Vona et al., 2015). The adsorption process using activated carbon is often applied to eliminate organic compounds in water treatment (Bhatnagar, Hogland, Marques, \& Sillanpää, 2013; Menya, Olupot, Storz, Lubwama, \& Kiros, 2018; Rivera-Utrilla et al., 2011; Yu et al., 2019).

Activated carbon is a term commonly used to denote carbon-based materials that have a fine internal pore structure. Activated carbon is produced from various

\footnotetext{
${ }^{*}$ Correspondence author.

E-mail: trih011@lipi.go.id (T.H. Jatmiko) 
carbon-rich materials such as biomass, coal, and lignite. Activated carbon has unique characteristics such as high surface area, large porosity with an internal pore structure consisting of micro, meso, and macropore and a broad spectrum of functional groups on the surface of activated carbon makes it applicable in many areas (Ahmed et al., 2019; Bhatnagar et al., 2013; González-García, 2018; Jaria, Silva, et al., 2019; Rivera-Utrilla et al., 2011; Yu et al., 2019).

An interesting raw material for activated carbon to be explored was an industrial waste. The utilization of waste into more useful materials will be a strategy towards an environmentally friendly and sustainable industry. One of the wastes that could be used as raw material for activated carbon was paper mill sludge (PMS) because of its high carbon content (Faubert, Barnabé, Bouchard, Côté, \& Villeneuve, 2016). PMS is a solid waste generated from the processing of liquid waste from the paper industry, which is usually only stockpiled, causing environmental problems (Faubert et al., 2016; Jaria, Calisto, et al., 2019; Jaria, Silva, et al., 2019). The use of PMS as activated carbon will increase added value economically and also solve environmental problems.

The purpose of this study was to determine the optimum conditions for activated carbon production to remove pharmaceutical wastewater using the Taguchi Grey relational analysis (GRA) method. The Taguchi method is a systematic experimental design and analysis. This method has proven to be a practical approach to produce high quality products at a relatively low cost as it can reduce the number of experiments carried out (Kasemsiri, Dulsang, Pongsa, Hiziroglu, \& Chindaprasirt, 2017; Lin, 2004; Roy, 2010). However, the Taguchi method is only designed to optimize one performance characteristic. For the multiresponse optimization problem, the Taguchi method is equipped with GRA (Datta, Bandyopadhyay, \& Pal, 2008; Kasemsiri et al., 2017; Lin, 2004).

\section{METHODS}

Data on activated carbon production, characteristics of activated carbon, and treatment of pharmaceutical wastewater with activated carbon were taken from Jaria et al. (2019). Activated carbon was made from primary paper mill sludge (PMS) from pulp and paper mill waste. Activated carbon was activated using $\mathrm{KOH}$ (Eka Pellet) or $\mathrm{K}_{2} \mathrm{CO}_{3}$ (AnalaR NORMAPUR) and pyrolyzed at $650{ }^{\circ} \mathrm{C}$ or $800{ }^{\circ} \mathrm{C}$ using muffle (Nüve, series MF 106) with a residence time of 60 minutes and 150 minutes. After that, activated carbon's characterization was carried out, including yield, surface area, and total organic carbon. The surface area of activated carbon was measured based on nitrogen isothermic adsorption using Micromeritics Instrument, Gemini VII 2380. Total organic carbon from activated carbon was determined using the TOC-VCPH Shimadzu equipped with a solid sample module SSM5000A.

Adsorption test of artificial pharmaceutical wastewater was done in batches. Pharmaceutical solutions of Carbamazepine (CBZ) from Sigma-Aldrich which were anti-epilepsy, antibiotic sulfamethoxazole (SMX) from TCI, and antidepressant paroxetine (PAR) from TCI were prepared separately with an initial concentration of $5 \mathrm{mgL}^{-}$ ${ }^{1}$. Each solution was contacted with $0.015 \mathrm{gL}^{-1}$ activated carbon overnight at $25^{\circ} \mathrm{C}$ and stirred at $80 \mathrm{rpm}$ in overhead shaker (Heidolph, Reax 2). After the solution filtered, the amount of absorbed waste was analyzed using a spectrophotometer (T90 + UV / visible Spectrometer) at a wavelength of $200 \mathrm{~nm}$ (SMX and PAR) and $214 \mathrm{~nm}$ for CBZ.

\section{Taguchi}

The Taguchi method was used to design experiments using orthogonal arrays. Experimental design using the Taguchi method will reduce the overall number of experiments (Roy, 2010). In this study, four factors (pyrolysis temperature, residence time, precursor:activating agent ratio, activating agent) with two levels were used to optimize the characteristic of activated carbon and its performance for pharmaceutical wastewater removal. The orthogonal array in the Taguchi method for the number of parameters 4 with two levels is L8. 


\section{Grey relation analysis}

The first stage in the grey relational analysis is grey relational formation. During this step, all experimental responses are normalized in the range between zero and one. Equation 1 is used to calculate the normalized value of the response with the expected value "the higher the better" (Datta et al., 2008; Kasemsiri et al., 2017; Lin, 2004).

$$
x_{i}^{*}(k)=\frac{x_{i}(k)-\min x_{i}(k)}{\max x_{i}(k)-\min x_{i}(k)}
$$

Where. $\mathrm{i}=1 . \ldots \mathrm{m} ; \quad \mathrm{k}=1 \ldots \mathrm{n}$;

$m$ is the number of experimental data,

$\mathrm{n}$ is the number of responses,

$\mathrm{x}_{\mathrm{i}}(\mathrm{k})$ the original sequence,

$\mathrm{x}_{\mathrm{i}}^{*}(\mathrm{k})$ the sequence after the data pre-processing.

$\max x_{i}(k)$ the biggest value of $x_{i}(k)$,

min $x_{i}(k)$ the smallest value of $x_{i}(k)$.

The coefficient of grey relational is decided from normalized data to describe the connection between the preferred and actual response.

$$
\xi_{i}(k)=\frac{\Delta_{\min }+\zeta \Delta_{\max }}{\Delta_{o i}(k)+\zeta \Delta_{\max }}
$$

Where $\Delta_{\mathrm{oi}}=\left|\mathrm{x}_{0}(\mathrm{k})-\mathrm{xi}(\mathrm{k})\right|$ is the deviation sequence, $\zeta$ is coefficient, usually taken as 0.5 .

Then, the grey relational level is calculated by the average of grey relational coefficient and overall evaluation of multiple performance characteristics is based on the degree of grey relationship.

\section{RESULT AND DISCUSSION}

The experimental design according to the orthogonal array from the Taguchi method for four factors with two levels, is shown in Table 1. Table 1 also shows the results of the experiment of activated carbon production along with its characteristics and performance in the adsorption of pharmaceutical wastewater. In general, SMX, CBZ, and PAR wastes could be adsorbed by activated carbon well. SMX could be absorbed by activated carbon with an absorption capacity of between $13 \pm 2 \%-80 \pm 2 \%$. CBZ that could be absorbed by activated carbon ranges from $6 \pm 1 \%-81 \pm 3 \%$, and PAR could be removed with activated carbon by $6 \pm 2 \%-81 \pm 1 \%$. The removal of pharmaceuticals by activated carbon depends on the activated carbon used to adsorb it. The higher the surface area of the activated carbon used, the higher the pharmaceuticals waste removal.

In the GRA evaluation, the first step was that the experimental data were normalized to a value between zero and one, commonly called gray relational generation.

\begin{tabular}{|c|c|c|c|c|c|c|c|c|c|c|}
\hline \multirow{3}{*}{ No. } & \multicolumn{4}{|c|}{ Factors } & \multicolumn{6}{|c|}{ Responses } \\
\hline & \multirow{2}{*}{$\mathrm{X} 1$} & \multirow{2}{*}{$\mathrm{X} 2$} & \multirow{2}{*}{$\mathrm{X} 3$} & \multirow{2}{*}{$\mathrm{X} 4$} & \multirow{2}{*}{$\begin{array}{l}\text { Yield } \\
(\%)\end{array}$} & \multirow{2}{*}{$\begin{array}{l}S_{\mathrm{BET}} \\
\left(\mathrm{m}^{2} \mathrm{~g}^{-1}\right)\end{array}$} & \multirow{2}{*}{ TOC (\%) } & \multicolumn{3}{|c|}{$\%$ Adsorption } \\
\hline & & & & & & & & SMX & $\mathrm{CBZ}$ & PAR \\
\hline 1 & 1 & 1 & 1 & 1 & 27.5 & 244 & $58 \pm 0.4$ & $13 \pm 2$ & $6 \pm 1$ & $8 \pm 2$ \\
\hline 2 & 1 & 1 & 2 & 2 & 7 & 523 & $54.9 \pm 0.5$ & $16 \pm 1$ & $6 \pm 1$ & $6 \pm 2$ \\
\hline 3 & 1 & 2 & 1 & 2 & 21.6 & 372 & $59 \pm 1$ & $14 \pm 3$ & $6 \pm 2$ & $9 \pm 2$ \\
\hline 4 & 1 & 2 & 2 & 1 & 5.2 & 766 & $54 \pm 1$ & $23 \pm 6$ & $13.8 \pm 0.3$ & $20 \pm 5$ \\
\hline 5 & 2 & 1 & 1 & 2 & 30 & 637 & $40 \pm 1$ & $19 \pm 5$ & $34 \pm 2$ & $54 \pm 2$ \\
\hline 6 & 2 & 1 & 2 & 1 & 3.7 & 1389 & $62.8 \pm 0.2$ & $80 \pm 2$ & $59 \pm 2$ & $70 \pm 4$ \\
\hline 7 & 2 & 2 & 1 & 1 & 26.4 & 1017 & $42.5 \pm 0.2$ & $23 \pm 3$ & $31 \pm 3$ & $55 \pm 3$ \\
\hline 8 & 2 & 2 & 2 & 2 & 2.7 & 1627 & $67 \pm 1$ & $71 \pm 1$ & $81 \pm 3$ & $81 \pm 1$ \\
\hline
\end{tabular}

Tabel 1. Orthogonal array of Taguchi L8 and multi response result (Jaria, Silva, et al., 2019)

$\mathrm{X} 1-$ Pyrolysis temperature $\left(650^{\circ} \mathrm{C}(-)\right.$ and $\left.800^{\circ} \mathrm{C}(+)\right)$.

$\mathrm{X} 2$-Residence time $(60 \mathrm{~min}(-)$ or $150 \mathrm{~min}(+))$.

X3-Precursor:activating agent ratio (10:1 (-) and 1:1 (+)).

$\mathrm{X} 4$-Activating agent $\left(\mathrm{K}_{2} \mathrm{CO}_{3}(-)\right.$ and $\left.\mathrm{KOH}(+)\right)$ 
Table 2. Normalize

\begin{tabular}{|c|c|c|c|c|c|c|}
\hline Run No. & Yield (\%) & $S_{\mathrm{BET}}\left(\mathrm{m}^{2} \mathrm{~g}^{-1}\right)$ & TOC (\%) & Ads (\%) SMX & Ads (\%) CBZ & Ads (\%) PAR \\
\hline 1 & 0.91 & 0.00 & 0.67 & 0.00 & 0.00 & 0.03 \\
\hline 2 & 0.16 & 0.20 & 0.55 & 0.04 & 0.00 & 0.00 \\
\hline 3 & 0.69 & 0.09 & 0.70 & 0.01 & 0.00 & 0.04 \\
\hline 4 & 0.09 & 0.38 & 0.52 & 0.15 & 0.10 & 0.19 \\
\hline 5 & 1.00 & 0.28 & 0.00 & 0.09 & 0.37 & 0.64 \\
\hline 6 & 0.04 & 0.83 & 0.84 & 1.00 & 0.71 & 0.85 \\
\hline 7 & 0.87 & 0.56 & 0.09 & 0.15 & 0.33 & 0.65 \\
\hline 8 & 0.00 & 1.00 & 1.00 & 0.87 & 1.00 & 1.00 \\
\hline
\end{tabular}

Table 3. Grey relational coefficient \& Grey relational grade

\begin{tabular}{|c|c|c|c|c|c|c|c|c|}
\hline Run No. & Yield (\%) & $\begin{array}{l}S_{\mathrm{BET}} \\
\left(\mathrm{m}^{2} \mathrm{~g}^{-1}\right)\end{array}$ & TOC (\%) & $\begin{array}{l}\text { Ads } \\
(\%) \\
\text { SMX }\end{array}$ & $\begin{array}{l}\text { Ads } \\
(\%) \\
\text { CBZ }\end{array}$ & $\begin{array}{l}\text { Ads } \\
(\%) \\
\text { PAR }\end{array}$ & GRG & Rank \\
\hline 1 & 0.85 & 0.33 & 0.60 & 0.33 & 0.33 & 0.34 & 0.46 & 5 \\
\hline 2 & 0.37 & 0.39 & 0.53 & 0.34 & 0.33 & 0.33 & 0.38 & 8 \\
\hline 3 & 0.62 & 0.36 & 0.63 & 0.34 & 0.33 & 0.34 & 0.44 & 6 \\
\hline 4 & 0.36 & 0.45 & 0.51 & 0.37 & 0.36 & 0.38 & 0.40 & 7 \\
\hline 5 & 1.00 & 0.41 & 0.33 & 0.35 & 0.44 & 0.58 & 0.52 & 3 \\
\hline 6 & 0.34 & 0.74 & 0.76 & 1.00 & 0.63 & 0.77 & 0.71 & 2 \\
\hline 7 & 0.79 & 0.53 & 0.36 & 0.37 & 0.43 & 0.59 & 0.51 & 4 \\
\hline 8 & 0.33 & 1.00 & 1.00 & 0.79 & 1.00 & 1.00 & 0.85 & 1 \\
\hline
\end{tabular}

Table 4. Factor

Level

Rank

\begin{tabular}{lcccc} 
& 1 & 2 & Delta & \\
\hline X1 & 0.42 & 0.65 & 0.23 & \\
X2 & 0.52 & 0.55 & 0.03 & 3 \\
X3 & 0.48 & 0.59 & 0.11 & 2 \\
X4 & 0.52 & 0.55 & 0.03 & 4 \\
\hline
\end{tabular}

Table 2 shows the normalized data for the characteristic of activated carbon and the adsorption of pharmaceutical wastewater. Then, based on normalized experimental data, gray relation coefficient calculations are performed to state the relationship between experimental data and desired results as shown in Table 3. So that optimization of complex multifarious respond characteristics can be transformed into the optimization of a single gray relational level. The optimal process parameters are shown by the highest gray relational level.

An overall evaluation of some process responses is based on a grey relational Grade (GRG). GRG is the average of the grey relational coefficient that corresponds to each response. The results of calculations and analysis of GRG values as shown in Table 3 , that the best performance was 
obtained on activated carbon in the $8^{\text {th }}$ experiment where all factors were at the highest level.

Table 4 shows the results of further calculations of the GRG difference for each parameter. It can be seen that the most influential factors in the production of activated carbon from waste with the best performance are X1, X3, $\mathrm{X} 2$ and finally X4. The highest temperature (X1) and the highest impregnation ratio (X3) are the most influential conditions in activated carbon production, whereas residence time (X2) and activating agent (X4) are less influential factors in activated carbon production. The results of this experiment show that temperature positively influences the development of porosity because activated carbon produced with a maximum pyrolysis temperature $\left(800{ }^{\circ} \mathrm{C}\right)$ has a high $S_{B E T}$ and the highest adsorption percentage for CBZ, SMX and PAR. The carbonization process is strongly influenced by temperature, presence of

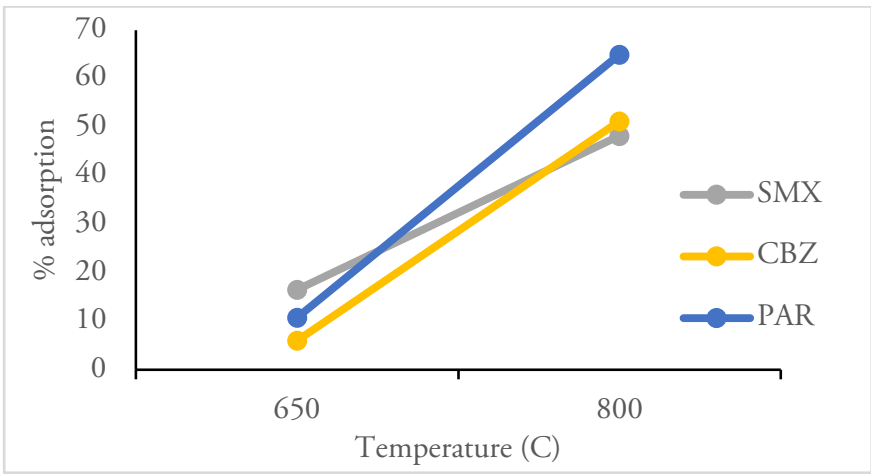

a

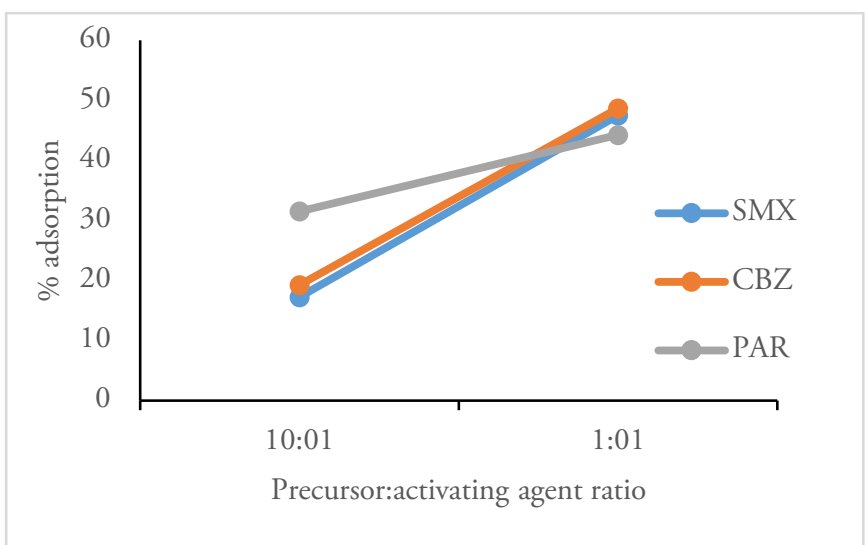

C inert gas, heating rate and residence time. A high carbonization temperature will produce a low yield because it produces more ash but good char quality (GonzálezGarcía, 2018).

Temperature of pyrolysis has the biggest effect on adsorption capacity of activated carbon. This phenomena correspondence with another study that the higher the pyrolysis temperature would increase the performance of activated carbon as seen in Figure 1a. The increase in pyrolysis temperature will cause more volatile content in the precursor to be released (Heidarinejad et al., 2020; Sun et al., 2014) so that it will increase the surface area of activated carbon due to the opening of the pores (Ahmad et al., 2012; Heidarinejad et al., 2020; Jaria, Silva, et al., 2019; Zhang, Liu, \& Liu, 2015). With the increase of surface area, the adsorption capacity of the activated carbon also increases, as seen in Figure 1a.

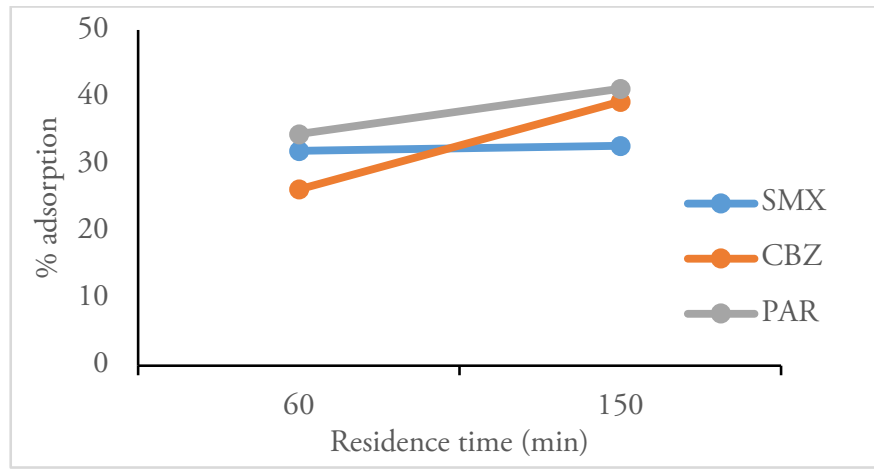

b

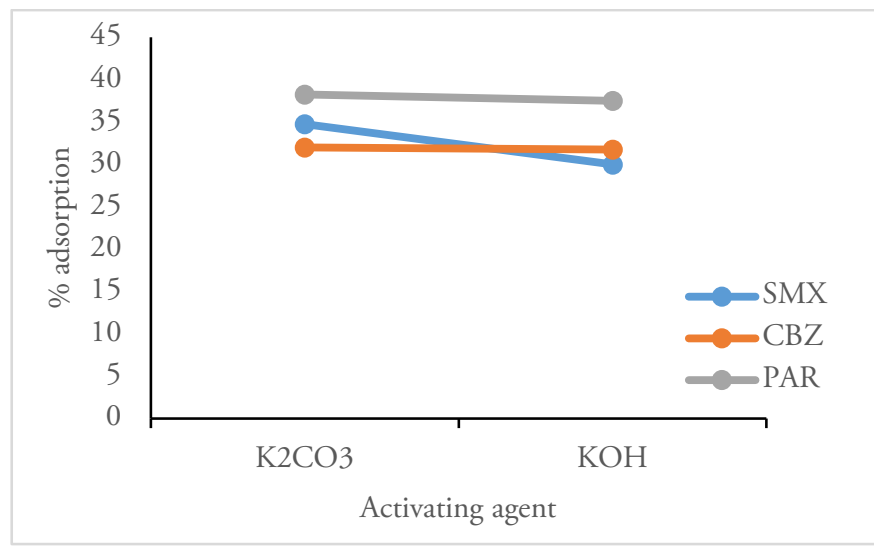

d

Figure 1. Effect operating condition on activated carbon adsorption performance a) temperature; b) Residence Time; c) Precursor:activating agent; d) Activating agent 
Table 5. Effect opertaing condition on activated carbon

\begin{tabular}{|c|c|c|c|c|}
\hline \multicolumn{2}{|c|}{ Operating condition } & \multirow{2}{*}{$\begin{array}{c}\text { Yield (\%) } \\
7\end{array}$} & \multirow{2}{*}{$\frac{S_{\mathrm{BET}}\left(\mathrm{m}^{2} \mathrm{~g}^{-1}\right)}{476,25}$} & \multirow{2}{*}{$\begin{array}{c}\text { TOC (\%) } \\
57\end{array}$} \\
\hline Tommentum $(C)$ & 650 & & & \\
\hline lemperature (c) & 800 & 30 & 1167,5 & 53,5 \\
\hline \multirow{2}{*}{ Time (min) } & 60 & 18,5 & 698,25 & 49 \\
\hline & 150 & 13,975 & 945,5 & 60 \\
\hline \multirow{2}{*}{ Precursor:activating agent } & $10: 1$ & 30 & 567,5 & 52,33 \\
\hline & $1: 1$ & 7 & 1076,25 & 60,5 \\
\hline \multirow{2}{*}{ Activating agent } & $\mathrm{K}_{2} \mathrm{CO}_{3}$ & 27,5 & 854 & 56 \\
\hline & $\mathrm{KOH}$ & 18,5 & 789,75 & 55,33 \\
\hline
\end{tabular}

Ratio precursor:activating agent also has affected to the activated carbon performance. Increasing the activating agent would activate precursor more optimum. In general, the activation process using chemicals will occur diffusion of chemicals into the precursors' internal structure so that it will open new pores and widen existing pores. When the activating agent $\left(\mathrm{K}_{2} \mathrm{CO}_{3}\right.$ or $\left.\mathrm{KOH}\right)$ was increased, the activation process becomes more optimal. The activated carbon formed has a high surface area and increases its ability to absorb adsorbate (Foo \& Hameed, 2012; Heidarinejad et al., 2020).

Increasing residence time will increase the quality of activated carbon, as shown in Figure $1 \mathrm{~b}$ and Table 5. The longest the residence time will increase the activated carbon processed more optimum, resulting in high surface area and TOC.

From the study results, as shown in Figure 1d and Table 5, activation using $\mathrm{K}_{2} \mathrm{CO}_{3}$ is slightly better than $\mathrm{KOH}$; this is in accordance with several previous studies (Abbas \& Ahmed, 2016; Heidarinejad et al., 2020). This is likely due to the ability of $\mathrm{K}_{2} \mathrm{CO}_{3}$ to inhibit the formation of tar and other liquid products during the pyrolysis process (Adinata, Wandaud, \& Aroua, 2007), so that activated carbon that is activated using $\mathrm{K}_{2} \mathrm{CO}_{3}$ has a slightly larger surface area and TOC than with activated carbon activated with $\mathrm{KOH}$.

\section{CONCLUSION}

Activated carbon produced from PMS waste shows satisfactory characteristics and adsorption performance of pharmaceutical wastewater. Multi-response analysis based on the Taguchi GRA method can illustrate well the factors that influence the production of active carbon from PMS waste. The most influential factors in the production of activated carbon are pyrolysis temperature $\left(800^{\circ} \mathrm{C}\right)$, ratio of precursors and activating agents (1:1), residence time (150 minutes) and finally the type of activator $(\mathrm{KOH})$.

\section{REFERENCE}

Abbas, A. F., \& Ahmed, M. J. (2016). Mesoporous activated carbon from date stones (Phoenix dactylifera L.) by one-step microwave assisted K2CO3 pyrolysis. Journal of Water Process Engineering, 201-207. https://doi.org/10.1016/j.jwpe.2016.01.004

Adinata, D., Wandaud, W., \& Aroua, M. (2007). Preparation and characterization of activated carbon from palm shell by chemical activation with K2CO3. Bioresource Technology, 98(1), 145-149. https://doi.org/10.1016/j.biortech.2005.11.006

Ahmad, M., Lee, S. S., Dou, X., Mohan, D., Sung, J.-K., Yang, J. E., \& Ok, Y. S. (2012). Effects of pyrolysis temperature on soybean stover- and peanut shellderived biochar properties and TCE adsorption in water. Bioresource Technology, 118, 536-544. https://doi.org/10.1016/j.biortech.2012.05.042

Ahmed, M. B., Hasan Johir, M. A., Zhou, J. L., Ngo, H. H., Nghiem, L. D., Richardson, C., ... Bryant, M. R. (2019). Activated carbon preparation from 
biomass feedstock: Clean production and carbon dioxide adsorption. Journal of Cleaner Production, 225 , 405-413. https://doi.org/10.1016/j.jclepro.2019.03.342

Bhatnagar, A., Hogland, W., Marques, M., \& Sillanpää, M. (2013). An overview of the modification methods of activated carbon for its water treatment applications. Chemical Engineering Journal, 219, 499-511.

https://doi.org/10.1016/j.cej.2012.12.038

Datta, S., Bandyopadhyay, A., \& Pal, P. K. (2008). Greybased taguchi method for optimization of bead geometry in submerged arc bead-on-plate welding. The International Journal of Advanced Manufacturing Technology, 39(11-12), 11361143. https://doi.org/10.1007/s00170-007-12836

Faubert, P., Barnabé, S., Bouchard, S., Côté, R., \& Villeneuve, C. (2016). Pulp and paper mill sludge management practices: What are the challenges to assess the impacts on greenhouse gas emissions? Resources, Conservation and Recycling, 108, 107133.

https://doi.org/10.1016/j.resconrec.2016.01.007

Foo, K. Y., \& Hameed, B. H. (2012). Preparation, characterization and evaluation of adsorptive properties of orange peel based activated carbon via microwave induced $\mathrm{K} 2 \mathrm{CO} 3$ activation. Bioresource Technology, 104, 679-686. https://doi.org/10.1016/j.biortech.2011.10.005

Gadipelly, C., Pérez-González, A., Yadav, G. D., Ortiz, I., Ibánez, R., Rathod, V. K., \& Marathe, K. V. (2014). Pharmaceutical Industry Wastewater: Review of the Technologies for Water Treatment and Reuse. Industrial \& Engineering Chemistry Research, 53(29), 11571-11592. https://doi.org/10.1021/ie501210j

González-García, P. (2018). Activated carbon from lignocellulosics precursors: A review of the synthesis methods, characterization techniques and applications. Renewable and Sustainable Energy
Reviews, 82

1393-1414.

https://doi.org/10.1016/j.rser.2017.04.117

Guo, Y., Qi, P. S., \& Liu, Y. Z. (2017). A Review on Advanced Treatment of Pharmaceutical Wastewater. IOP Conference Series: Earth and Environmental Science, 63, 012025. https://doi.org/10.1088/1755-1315/63/1/012025

Heidarinejad, Z., Dehghani, M. H., Heidari, M., Javedan, G., Ali, I., \& Sillanpää, M. (2020). Methods for preparation and activation of activated carbon: a review. Environmental Chemistry Letters, 18(2), 393-415. https://doi.org/10.1007/s10311-01900955-0

Jaria, G., Calisto, V., Silva, C. P., Gil, M. V., Otero, M., \& Esteves, V. I. (2019). Obtaining granular activated carbon from paper mill sludge - A challenge for application in the removal of pharmaceuticals from wastewater. Science of The Total Environment, 653, 393-400.

https://doi.org/10.1016/j.scitotenv.2018.10.346

Jaria, G., Silva, C. P., Oliveira, J. A. B. P., Santos, S. M., Gil, M. V., Otero, M., ... Esteves, V. I. (2019). Production of highly efficient activated carbons from industrial wastes for the removal of pharmaceuticals from water-A full factorial design. Journal of Hazardous Materials, 370, 212218.

https://doi.org/10.1016/j.jhazmat.2018.02.053

Kasemsiri, P., Dulsang, N., Pongsa, U., Hiziroglu, S., \& Chindaprasirt, P. (2017). Optimization of Biodegradable Foam Composites from Cassava Starch, Oil Palm Fiber, Chitosan and Palm Oil Using Taguchi Method and Grey Relational Analysis. Journal of Polymers and the Environment, 25(2), 378-390. https://doi.org/10.1007/s10924016-0818-z

Li, X., \& Li, G. (2015). A Review: Pharmaceutical Wastewater Treatment Technology and Research in China. In Proceedings of the 2015 Asia-Pacific Energy Equipment Engineering Research Conference. Zhuai City, China: Atlantis Press. 
https://doi.org/10.2991/ap3er-15.2015.81

Lin, C. L. (2004). Use of the Taguchi Method and Grey Relational Analysis to Optimize Turning Operations with Multiple Performance Characteristics. Materials and Manufacturing Processes, 19(2), 209-220. https://doi.org/10.1081/AMP-120029852

Menya, E., Olupot, P. W., Storz, H., Lubwama, M., \& Kiros, Y. (2018). Production and performance of activated carbon from rice husks for removal of natural organic matter from water: A review. Chemical Engineering Research and Design, 129, 271-296.

https://doi.org/10.1016/j.cherd.2017.11.008

Pal, P. (2018). Treatment and Disposal of Pharmaceutical Wastewater: Toward the Sustainable Strategy. Separation \& Purification Reviews, 47(3), 179-198. https://doi.org/10.1080/15422119.2017.1354888

Pereira, J. M., Calisto, V., \& Santos, S. M. (2019). Computational optimization of bioadsorbents for the removal of pharmaceuticals from water. Journal of Molecular Liquids, 279, 669-676. https://doi.org/10.1016/j.molliq.2019.01.167

Rana, R. S., Singh, P., Kandari, V., Singh, R., Dobhal, R., \& Gupta, S. (2017). A review on characterization and bioremediation of pharmaceutical industries' wastewater: an Indian perspective. Applied Water Science, $\quad 7(1), \quad 1-12$. https://doi.org/10.1007/s13201-014-0225-3

Rivera-Utrilla, J., Sánchez-Polo, M., Gómez-Serrano, V., Álvarez, P. M., Alvim-Ferraz, M. C. M., \& Dias, J.
M. (2011). Activated carbon modifications to enhance its water treatment applications. An overview. Journal of Hazardous Materials, 187(1), $1-23$.

https://doi.org/10.1016/j.jhazmat.2011.01.033

Roy, R. K. (2010). A primer on the Taguchi method (2nd ed). Dearborn, MI: Society of Manufacturing Engineers.

Sun, Y., Gao, B., Yao, Y., Fang, J., Zhang, M., Zhou, Y., ... Yang, L. (2014). Effects of feedstock type, production method, and pyrolysis temperature on biochar and hydrochar properties. Chemical Engineering Journal, 240, 574-578. https://doi.org/10.1016/j.cej.2013.10.081

Vona, A., di Martino, F., Garcia-Ivars, J., Picó, Y., Mendoza-Roca, J.-A., \& Iborra-Clar, M.-I. (2015). Comparison of different removal techniques for selected pharmaceuticals. Journal of Water Process Engineering, $\quad 5, \quad 48-57$. https://doi.org/10.1016/j.jwpe.2014.12.011

Yu, L.-J., Rengasamy, K., Lim, K.-Y., Tan, L.-S., Tarawneh, M., Zulkoffli, Z. B., \& Se Yong, E. N. (2019). Comparison of activated carbon and zeolites' filtering efficiency in freshwater. Journal of Environmental Chemical Engineering, 7(4), 103223. https://doi.org/10.1016/j.jece.2019.103223

Zhang, J., Liu, J., \& Liu, R. (2015). Effects of pyrolysis temperature and heating time on biochar obtained from the pyrolysis of straw and lignosulfonate. Bioresource Technology, 176, 288-291. https://doi.org/10.1016/j.biortech.2014.11.011. 